\title{
BOA DELIBERAÇÃO (EUBOULÍA) E O PROBLEMA DA MORALIDADE DOS MEIOS EM ARISTÓTELES*
}

\author{
Jaqueline Stefani** \\ http://orcid.org/0000-0002-2421-4965 \\ jaquelinestefani@yahoo.com.br
}

RESUMO O escopo da pesquisa é a análise de 1142b 17-28 da "Ética Nicomaqueia", trecho em que Aristóteles disserta sobre a correção (orthotes), tendo em vista que a boa deliberação (euboulía) é uma espécie de correção. A passagem não é clara e sugere que: i) na boa deliberação, a moralidade restringe-se aos fins, cabendo aos meios apenas a característica de serem eficazes na obtenção dos fins; ou que ii) na boa deliberação, a moralidade recai sobre meios e sobre fins pois, com a expressão "usar os meios corretos na obtenção do fim", Aristóteles estaria incluindo o critério moral dos meios como condição necessária à boa deliberação. Opto por “i)" e defendo que a boa deliberação consiste tão somente em uma habilidade exitosa na obtenção de um fim bom, habilidade que leva em conta o que é melhor, mais fácil, mais eficaz, feita em tempo oportuno.

Palavras-chave Aristóteles; "Ética Nicomaqueia”; boa deliberação; correção; moralidade dos meios.

ABSTRACT The scope of research is the analysis of "Nicomachean Ethics", section 1142b 17-28, a passage in which Aristotle discusses the correction (orthotes), since good deliberation (euboulía) is a kind of correction. The passage is not clear and suggests that: i) in good deliberation, morality is

** Universidade de Caxias do Sul. Caxias do Sul, RS, Brasil. 
restricted to the ends, the means having only the characteristic of being effective in attaining the ends; or that ii) in good deliberation, morality pertains to means and ends since, in the expression "to use the right means in obtaining the end", Aristotle seems to include the moral criterion of means as a necessary condition for good deliberation. I opt for "i)" and argue that good deliberation consists only in a successful ability to attain a good end, a skill that takes into account what is better, easier, more effective, done in a timely manner.

Keywords Aristotle; "Nicomachean Ethics"; Good deliberation; Correction; Morality of means.

\section{Introdução}

No Livro VI da "Ética Nicomaqueia" (EN), Aristóteles analisa que tipo de correção (orthotes) é a boa deliberação (euboulía), afirmando que a boa deliberação tem como características necessárias: i) a bondade do fim; ii) a eficiência dos meios, no sentido em que os meios devem ser corretos; e iii) a oportunidade no tempo. Contudo, o que significa, propriamente, "meios corretos"? Das características que são individualmente necessárias e conjuntamente suficientes para definir a boa deliberação a dúvida recai sobre "ii)": "meio correto" significa apenas meio eficaz para a obtenção do fim ou carrega um sentido ético de "moralmente correto"? Pode-se ainda perguntar: é possível à boa deliberação o uso de meios ignóbeis para atingir um fim bom? Em última instância: os fins justificam os meios?

Tal análise é objeto de interessante controvérsia interpretativa e tem implicações diretas sobre a sabedoria prática (phronesis) tendo em vista que, se o agente é prudente, então possui boa deliberação e a boa deliberação é uma espécie de correção. A relevância maior está na obscuridade do trecho que pode sugerir que na boa deliberação a moralidade dos meios é irrelevante, sendo possível o uso de quaisquer meios para atingir um fim bom, contanto que a deliberação tenha por fim um bem, seja feita corretamente, ou seja, no tempo oportuno e com a habilidade de encontrar o melhor meio. Contudo, a análise de $E N, 1142$ b 17-28, pode igualmente sugerir que na boa deliberação é necessário que os meios escolhidos para atingir um fim bom sejam, eles próprios, moralmente bons, pois o que Aristóteles pretende com a expressão "usar os meios corretos na obtenção do fim" é assinalar o caso em que os fins não justificam os meios, ou seja, que os meios devem ser moralmente bons e que isso é condição necessária à boa deliberação. 
A escolha sobre uma ou outra interpretação leva o leitor a assumir teses adjacentes. Quem assume que a correção nos meios significa apenas que eles devem ser eficazes na obtenção dos fins terá de explicar como Aristóteles faz recair o peso da responsabilidade moral sobre a escolha deliberada (proaíresis), se a escolha deliberada é sempre uma decisão sobre os meios, sobre aquilo que leva aos fins (ta pros ta tele), e nunca sobre os fins. Contudo, quem sustenta que os meios devem ser moralmente bons, e que isso é condição necessária à boa deliberação, terá de encontrar base textual na $E N$ para defender a moralidade dos meios como requisito necessário à boa deliberação - base textual aparentemente inexistente -, para livrar tal postura do estigma de uma leitura moderna tendenciosa, que não condiz com o sentido original do texto grego, pois não parece uma preocupação aristotélica alertar contra uma postura maquiavélica sobre meios e fins.

O problema é colocado do seguinte modo: é permitido, segundo a $E N$, que se utilize qualquer meio para se atingir um fim bom? Pergunta atual e pertinente à discussão ética hodierna.

\section{Phronesis, deliberação e escolha deliberada}

A definição de prudente (phronimos) é apresentada por Aristóteles no Livro VI da $E N$ como sendo aquele que possui os meios mais adequados para obter um fim louvável. Quem tem prudência é capaz de deliberar bem, calcular retamente sobre o que é bom e o que contribui para a vida boa em geral, sendo a phronesis uma capacidade de escolher o melhor modo de agir com referência ao que é bom ou mal, vantajoso ou desvantajoso, tendo em vista, sempre, a melhor das coisas alcançáveis. Tal virtude intelectual prática é característica daquele que sabe o que é bom para si e possui certa capacidade de previsão no que tange às coisas que lhe dizem respeito. Desse modo, de acordo com Aristóteles (EN, 1141b4-1142a5), a sabedoria prática parece referir-se ao próprio agente, indivíduo que conhece e se ocupa com seus interesses. Assim é que Anaxágoras e Tales, pessoas dotadas de sabedoria filosófica (sophia), mas não prática (phronesis), ignoram o que lhes é vantajoso.

Contudo, segundo Aristóteles (EN, 1142a1-10), a existência de um bem individual parece estar vinculada à existência de elementos externos, como um bem familiar, uma forma razoável de governo etc., de modo que o bem de cada um teria relação com um bem mais amplo. ${ }^{1}$ Seria, de fato, improvável crer que 
é possível ter uma vida boa, plena, feliz, tendo alcançado o maior bem para si, quando se é governado por um tirano ou se seus filhos estão sendo torturados ou seus pais assassinados. Além disso, o melhor dos homens é aquele que consegue o que é mais difícil de realizar no plano moral: praticar a virtude para com o outro. Dito de outro modo, a excelência ética no mais alto grau é aquela que é exercida não apenas naquelas coisas que dizem respeito ao próprio agente, mas naquelas que envolvem a relação com outrem.

O phronimos tem a capacidade deliberativa em um grau excelente e a boa deliberação é uma correção, em certa medida, da deliberação. Aristóteles examina a deliberação (bouleusis) e a escolha deliberada (proaíresis), no Livro III, caracterizando a deliberação como uma capacidade de calcular, de pesar razões, de aquilatar adequadamente os elementos nas circunstâncias particulares, analisando prós e contras, procurando os melhores meios para atingir um fim, "meio" entendido como "aquilo que é com vistas a um fim" (ton pros ta tele). ${ }^{2}$ Além disso, deliberar não é ainda escolher; caracteriza-se como uma investigação acerca de coisas que estão em nosso poder fazê-las ou não (eph'hemin), que estão ao alcance e cujo resultado é indefinido. Sobre o necessário e sobre o acaso não se delibera. ${ }^{3}$

Assim, a deliberação é uma ação da racionalidade prática que tem por objeto o possível, o alcançável e refere-se àquilo que é com vistas a um fim. ${ }^{4} \mathrm{O}$ objetivo a ser alcançado pela deliberação, o fim que se quer atingir, é posto pelo querer (boulesis), que depende, por sua vez, do caráter do agente e, portanto, das virtudes (ou vícios) morais, cabendo à deliberação ponderar sobre o melhor meio para atingi-lo.

O fim, sendo aquilo que se quer alcançar, será um bem - não só um bem aparente, mas real - se o agente for virtuoso; do contrário, será um mal, ainda que para o agente pareça ser um bem, dado que todos buscam o que lhes parece bom (Aristóteles, EN, 1113a 24). ${ }^{5}$ Todos buscam o que lhes causa prazer e fogem do que lhes causa dor: virtuoso é o agente que sente prazer e dor com

é aquele que vê o que deve ser feito não só para si, mas também para os outros)" (Zingano, 2008, p. 161).

Uma questão interessante, que não será analisada aqui, é: se a escolha é apenas sobre meios e não sobre fins, e se o desejo é responsável pelos fins ao passo que a deliberação é razão dos meios, por que a escolha, que é razão e desejo, não é também sobre fins, mas apenas sobre meios?

3 Em EN 1112b5-10, Aristóteles afirma que o objeto de deliberação é aquilo cuja ocorrência é no mais das

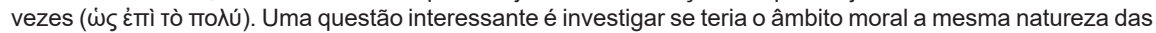
ocorrências no mais das vezes discutidas na Física, natureza essa regida por uma necessidade complexa. E isso se referiria ao caráter do agente, por exemplo, pessoas que frequentemente agem de um determinado modo tenderão a agir da mesma maneira em ações futuras? Tal questão não será abordada aqui pois necessitaria de longa análise e perder-se-ia o objetivo proposto neste artigo.

4 Nas palavras de Pakaluk "Quando há vários caminhos para um determinado fim, a deliberação requer que localizemos o melhor caminho, e esse melhor caminho varia de caso a caso" (2008, p. 139).

5 Tese afirmada também em Metafísica 1072a 28 e Tópicos 147a 1-5. 
as coisas certas, no momento certo, do modo certo, com a pessoa ou coisa certa, na quantidade certa, com a finalidade certa etc. Por isso, o prazer e a dor, dependendo de como são sentidos, com quê, quando, quanto, com que fim etc., indicam o caráter do agente, donde se segue a importância ímpar da educação dos desejos, pois é por ela que se aprende a sentir prazer e dor com as coisas certas.

Com respeito aos objetos de escolha (o nobre, o agradável e o útil), o virtuoso age corretamente e o vicioso erroneamente (Aristóteles, EN, 1104b 30). De fato, o critério distintivo do virtuoso é a percepção correta das coisas em todos os âmbitos. Contudo, a determinação do que é ou não certo é difícil, pois há vários modos pelos quais se pode errar, mas apenas um modo de acertar. Tal análise necessária em um processo de escolha sempre vai ter de levar em conta as circunstâncias particulares da ação.

Não se discute o fim pois, em certo sentido, sobre ele não há controvérsia:

Deliberamos não sobre os fins, mas sobre as coisas que conduzem aos fins. Com efeito, nem o médico delibera se há curar, nem o orador se há de convencer [...] mas, tendo posto um fim, investigam como e através de que o obterão; e, parecendo ocorrer através de vários meios, investigam através de qual mais rápida e belamente ocorrerá; sendo produzido por um único meio investigam como ocorrerá através disto e este através de que meio, até chegarem à primeira causa, que é a última na ordem de descoberta. (Aristóteles, EN, 1112b 10-19) ${ }^{6}$

Conforme Aristóteles, portanto, a natureza das questões sobre as quais opera a deliberação envolve: i) possibilidade, dado que não se delibera sobre o impossível nem sobre o necessário; ii) estar ao nosso alcance, pois se nada pode ser feito pelo agente em questão, então não há razões para ele deliberar; e iii) a deliberação é sempre sobre aquilo que leva ao fim, jamais sobre o fim. Em síntese, o objetivo da deliberação é sempre encontrar o melhor caminho para atingir um fim, caminho que seja possível e esteja ao alcance.

Em EN 1111b, Aristóteles investiga a escolha deliberada analisada com relação ao querer (boulesis), ao apetite (epithumia), ao ímpeto (thumos) e à opinião (doxa), concluindo que não há identidade entre escolha e qualquer uma dessas outras coisas, dado que os três tipos de desejos (querer, ímpeto e apetite) relacionam-se com prazer e dor, ou com o fim, ao passo que a escolha envolve deliberação racional, refere-se aos meios que levam a um fim e relacionase com o bem e o mal. A principal distinção entre querer e escolha é que o primeiro pode referir-se ao que esteja fora do alcance do agente, como querer 
a imortalidade, ao passo que a escolha refere-se sempre ao que está ao alcance do agente. Também não há identificação da escolha com a opinião, que diz respeito ao verdadeiro e ao falso e não ao o bem e ao mal.

A escolha, então: i) refere-se ao que é possível; ii) relaciona-se com o meio que leva a um fim e não com o fim; iii) faz parte da parte racional da alma; iv) não se relaciona com prazer e dor, mas com bem e mal; v) depende de nós; e vi) é uma decisão que envolve razão e desejo: a escolha é o que é desejado após deliberação. A grande diferença entre deliberação e escolha é que na escolha é necessário que se queira agir conforme o resultado racional operado pela deliberação, mas na deliberação não. Por isso Aristóteles ( $E N$, 1113a 9) afirma que a escolha é um "desejo deliberado", sendo a deliberação um processo apenas racional.

A escolha deliberada é o lugar mais próprio da avaliação do caráter do agente, como afirma Aristóteles em EN 1111b 5, sendo condição suficiente para a responsabilidade moral, de modo que, se há escolha deliberada, então há responsabilidade moral ou, dito de outro modo, "Se x escolhe deliberadamente fazer F, então x é responsável moralmente por F". O julgamento moral não pode basear-se apenas na análise da ação moral, havendo um rol de elementos adicionais para que se possa proceder a um exame do caráter. A razão de tal ressalva é que uma ação aparentemente louvável pode ser praticada apenas por medo de uma repreensão legal ou uma censura social, caso em que o agente não é virtuoso.

A caracterização de uma ação virtuosa requer que o agente i) seja princípio da ação e conheça o que faz, que a ação seja, portanto, uma ação voluntária; ii) delibere bem (levando em conta o meio termo e a reta razão); iii) escolha agir conforme o resultado da deliberação; e iv) aja por um caráter firme e imutável ${ }^{7}$ (Aristóteles, EN, 1105a 34). Assim, além da ação, há que se examinar o caráter do agente, o modo como lida com seus desejos, com prazeres e dores, se possui ou não as virtudes morais, pois esses são os elementos responsáveis pelo modo como tal agente põe o fim, que é o objetivo, o alvo para o qual ele elege o melhor meio através da escolha deliberada.

\section{A boa deliberação: possibilidades interpretativas}

A deliberação, principal característica da phronesis, não é qualquer deliberação, mas uma boa deliberação (euboulía), que é a excelência no

7 Para a questão da possibilidade ou não de mudança de caráter na ética aristotélica, ver Carvalho e Stefani (2016, pp. 93-110). 
deliberar e uma espécie de correção. Em EN 1144a 23-28, Aristóteles faz uma esclarecedora análise sobre a habilidade, comparando-a com a sabedoria prática, afirmando que ambas são competentes para a obtenção do fim, a saber, ambas deliberam com êxito. Contudo, o prudente sempre visa a um fim bom, dado que ele possui as virtudes do caráter, ao passo que o habilidoso pode visar a um fim mau. Louvada é a habilidade quando se apresenta a serviço de um fim bom; quando o fim é mau, a habilidade é reprovada e chamada, mais propriamente, de ardil (panourgía). Bodéüs (2004) ressalta ${ }^{8}$ a diferença entre deliberação e boa deliberação por meio da análise de $E N$ 1144a 25: a deliberação é uma habilidade exitosa de pesar prós e contras, elegendo o melhor meio ou o mais correto, no tempo oportuno, de atingir um fim, independente da qualidade do fim. Quando o fim é mau, a capacidade deliberativa merece censura; quando o fim é bom, contudo, tal capacidade merece louvor.

Claro é que a deliberação não carrega um sentido moral, pois trata-se de uma habilidade capaz de escolher os melhores meios para se atingir um fim qualquer. Mas o que dizer da boa deliberação? No Livro VI, há uma passagem conhecida que, por ser central à questão aqui discutida, vale a transcrição na íntegra: ${ }^{9}$

(1) o acrático e o vicioso alcançam o que se propuseram alcançar pelo raciocínio, de modo que deliberaram corretamente, mas colhem um grande mal. No entanto, parece que o bem deliberar é um bem, pois a boa deliberação é a correção da deliberação que alcança o bem. (2) Mas é possível alcançá-lo por um silogismo falso, isto é, alcançar aquilo que se deve fazer, mas não alcançar aquilo através de que se deve fazê-lo - é possível ser falso o termo mediador. Por conseguinte, ainda não é boa deliberação aquela em que se alcança o que se deve alcançar, mas não do modo pelo qual se deveria alcançar. Além disso, (3) é possível alcançá-lo depois de deliberar por muito tempo, mas o bom deliberador o alcança rapidamente. Então, nem sequer a primeira seria uma boa deliberação, mas o seria a correção de acordo com o proveitoso, e do objeto devido, no modo e no tempo devido. (Aristóteles, EN, 1142b17-28, grifos meus)

É pacífico entre os comentadores aristotélicos que a boa deliberação tem como características necessárias: i) a bondade do fim; ii) a eficiência dos meios; e iii) a oportunidade no tempo. Contudo, pode-se perguntar se tais características são suficientes para definir a boa deliberação ou se seria necessário acrescentar iv) a bondade dos meios.

8 "Um e outra [o ardil e a prudência] implicam a mesma habilidade, que consiste em poder executar tudo o que permite atingir um dado objetivo, mas, explica Aristóteles, esta habilidade é ardil quando o objetivo que se visa é vil, enquanto é sagacidade [prudência] quando é belo e louvável" (Bodéüs, 2004, pp. 82, 83).

9 Cito, aqui, a tradução de Lucas Angioni, publicada na Revista Dissertatio [34], pp. 285-300, verão de 2011 (pp. 294, 295). 
Para Gauthier-Jolif (2002, pp. 516, 517), a moralidade dos meios está claramente posta na passagem 1142b 23-28: "a ideia de dever moral aflora no pensamento de Aristóteles" (p. 516) e "Aristóteles reconhece expressamente que o fim não justifica os meios, mas que eles têm, por si mesmos, um valor moral" (p. 517, grifos meus). É no mínimo curioso atribuir a Aristóteles as noções de um dever moral que aflora e de um fim que não justifica os meios. Parece, antes, um desejo de ler no texto Aristotélico noções que lhe são estranhas e que fazem parte de um pensamento filosófico datado posteriormente, como bem afirma Aubenque (2008, p. 219). ${ }^{10}$ É difícil ver no texto aristotélico uma noção de "meio" independente de um fim; mais difícil ainda é ver uma oposição entre ambos.

Ao que parece, é no mínimo descabida a afirmação "Aristóteles reconhece expressamente que o fim não justifica os meios", pois "meio" é aquilo que é com vistas a um fim e que é escolhido, sendo objeto do querer do agente e resultado de deliberação racional. A escolha do meio que leva ao fim requer não só uma razão deliberativa, mas igualmente a anuência do agente à conclusão da deliberação. Os fins, contudo, são dados pelo querer, e queremos ou desejamos de acordo com nosso caráter, caráter responsável tanto por tomar determinado fim como bom quanto por escolher determinado meio em detrimento de outros. Se fosse possível, o que não parece o caso, que Aristóteles concebesse certa cisão e independência entre meios e fins, então o agente que escolhesse meios ignóbeis (sendo que havia meio melhor, moralmente falando, como possibilidade) para atingir um fim bom, sofreria de uma esquizofrenia do querer, pois quereria e não quereria o bem ao mesmo tempo e sob o mesmo aspecto. Tal separação e independência não aparecem em lugar algum da $E N$. Diferente é o exemplo aristotélico de alguém que quer um fim bom, mas erra na escolha dos meios: o erro seria de outra natureza, não de natureza moral. A natureza do erro, referida por Aristóteles, pode ser de ordem lógica, o que será explicado mais à frente, ou técnica, no sentido em que se escolhe o meio mais difícil, menos eficaz e/ou mais longo para se atingir um fim bom, sendo que havia uma forma mais fácil, melhor e/ou mais rápida. É o caso em que há erro no cálculo, mas, a despeito de uma deliberação inábil, atinge-se um bem. Tais são os exemplos a que (2) parece se referir.

O agente é moralmente responsável pela escolha dos meios que levam ao fim, se i) quer alcançar o fim; ii) conhece as circunstâncias particulares nas

10 "É tentador para um leitor moderno, projetar sobre alguns dos textos de Aristóteles a problemática moral que nasce da constatação de uma contradição entre o fim e os meios: a retidão do fim justifica sua obtenção por meios intrinsecamente maus? De fato, parece que Aristóteles nunca pressentiu tal problema". 
quais a ação ocorre; e iii) é o princípio motor da decisão que toma. Assim, está em seu poder agir de uma forma ou de outra. No entanto, não parece razoável interpretar que a questão moderna (sobre se podemos usar quaisquer meios para atingir um fim) era uma questão aristotélica. O que parece é que aquilo em vistas do fim sobre o qual se delibera, e que é objeto de escolha, depende, como atesta a própria expressão, do fim. Depende, pois sem um fim que se queira alcançar, não haverá deliberação sobre meios; em contrapartida, dado um fim qualquer, todo o raciocínio calculativo empregado no processo deliberativo é feito por causa deste fim, para alcançá-lo. Desse modo, não parece possível que o desejo, implicado na escolha por um meio ignóbil para atingir um fim, seja contrário ao desejo, que toma um fim como bom (e que é, de fato, um bem). $\mathrm{O}$ que significa que a responsabilidade moral decorrente da escolha dos meios que levam a um fim depende i) da excelência da deliberação - no sentido que ela deve conduzir ao fim no tempo adequado, de modo eficaz - e ii) da qualidade do fim, que é fruto imediato do querer e do caráter. Como o agente é, de certo modo, responsável pela formação do próprio caráter, em última instância, e por transitividade, ele é responsável pelo fim que deseja.

Irwin (1999, p. 248), sobre o trecho da $E N 1142$ b 17-28, no que se refere ao caso "(1)" (caso do incontinente em que o fim é um mal, mas a habilidade deliberativa é exitosa), afirma que:

Uma pessoa viciosa pode deliberar corretamente sobre os modos de obter dinheiro desonestamente. Em um aspecto, então, ele alcança um bem, uma vez que a riqueza é um bem. Em outro aspecto, porém, ele deixa de alcançar um bem, uma vez que a riqueza não é boa para ele, dado que ele é vicioso. Este segundo aspecto é o que Aristóteles tem em mente aqui. (Irwin, 1999, p. 248)

A análise de Irwin sobre o caso "(1)" é interessante, pois exemplifica um homem vicioso que é hábil na deliberação mas tal habilidade é desonesta. No caso aludido, o fim alcançado é um mal para o agente, ainda que lhe pareça um bem, pois o fim sempre aparece como um bem para aquele que o persegue e a riqueza não é um bem sem mais: para o virtuoso, a riqueza é um bem; contudo, a riqueza é prejudicial a muitos (Aristóteles, EN, 1094a 7-b 17) sendo apenas algo útil, um meio desejado sempre com vistas a outra coisa. Em contrapartida, ainda que se tomasse a riqueza como um bem em si, sem mais, independentemente se é um vicioso ou um prudente que a persegue como fim, se fossem utilizados meios honestos para alcançá-la, e não, como no caso apresentado por Irwin, meios desonestos, então o agente em questão teria a característica da boa deliberação? Por exemplo: um vicioso tem por fim alcançar riqueza; para tanto, joga e ganha em algum jogo de azar lícito. 
Poderíamos tomar tal agente como alguém dotado de euboulía? Ao que tudo indica, a resposta aristotélica seria negativa.

A euboulía necessita que o fim almejado seja um bem. No caso da riqueza, que considerada isoladamente é um bem, para que seja considerada um bem no contexto de uma ação, devem ser levadas em conta as circunstâncias particulares, tais como: quem é o agente, que caráter possui, que recursos possui, como agirá para alcançar tal fim, qual o objetivo de alcançar o fim a que almeja etc. (Aristóteles, $E N, 1122$ b 24). Diferente é tomar o fim independentemente dos meios, cisão que Aristóteles não parece ter considerado. Os meios são meios-em-vista-de-um-fim que são tidos como um mal ou um bem em uma circunstância particular de ação que, no caso que se discute aqui, envolve euboulía.

Quem possui a capacidade da boa deliberação tem como marca de suas ações a retidão na escolha do melhor modo de atingir um fim bom. Assim, a um vicioso não é possível agir com boa deliberação, pois os fins que persegue não são bens. Além disso, ainda que o exemplo tivesse como fim a felicidade, tida como bem absoluto, não poderíamos considerar um caso de euboulía, dado que um vicioso falharia, inevitavelmente, na escolha do caminho que leva ao fim, pois para ser feliz é necessário ao agente ser virtuoso.

Irwin, analisando o caso "(2)" (caso em que se alcança o fim, que é um bem, mas não pelo meio correto), afirma que

O bom deliberador, e portanto o prudente e a pessoa virtuosa, deve alcançar a conclusão correta pelo método correto. Se minha deliberação me disser corretamente que não devo roubar agora, mas não me diz isso pelas razões certas (se, por exemplo, me diz que não devo roubar simplesmente porque é provável que seja descoberto ou porque a vítima é um amigo meu), não é uma boa deliberação. (Irwin, 1999, pp. 248, 249, grifos meus)

No caso "(2)", em contrapartida, não parece que o que Aristóteles tinha em mente fosse um vicioso, pois diz respeito a alguém que alcança o bem, chegando "ao que se deve fazer", mas sem excelência no deliberar. Alcançar a riqueza pelos motivos aludidos acima tampouco se refere a um fim bom, de modo que o exemplo aristotélico supõe fim bom e erro na deliberação, e o exemplo de Irwin não supõe. Irwin, por sua vez, insere a noção de "razão certa" na deliberação: a deliberação correta indicaria que roubar não é o melhor meio para se atingir a riqueza, mas poderia fazer isso pelos motivos corretos ou não; se faz isso pelas razões incorretas, então não se trataria aqui de boa deliberação.

Segundo Gottlieb (2009, p. 212), Tomás de Aquino afirma que o caso (2) significa que o agente chegou a um fim bom, mas pelos meios moralmente incorretos. O exemplo tomasiano é o seguinte: "P1: Meu objetivo é ajudar aos 
pobres. P2: Roubar é a maneira correta de ajudar aos pobres. Conclusão: Eu devo roubar isto". Gottlieb assinala que este caso apresenta conclusão falsa, mas o caso aristotélico em (2) requer conclusão verdadeira estando o erro no termo médio. A proposta da autora é a seguinte: "P1: Pessoas generosas devem ajudar os pobres (no momento certo, com os recursos certos, etc.). P2: Eu sou uma pessoa generosa. Esta é uma pessoa pobre que precisa de ajuda. Estes são os recursos certos, etc. Conclusão: Eu devo ajudar esta pessoa" (p. 213). O erro estaria na segunda premissa (em itálico), pois o agente não é uma pessoa generosa e não reconhece quais são os meios corretos para ajudar, tomando o roubo como a melhor opção.

Mas que tipo de erro é esse? É um erro moral? Ou um erro de percepção ou de razão? Aristóteles ressalta que o erro na deliberação pode ser tanto no que se refere ao universal quanto no que se refere ao particular, "tanto é possível ignorar que toda água pesada é má como que esta água aqui presente é pesada" (Aristóteles, $E N, 1142$ a 20), sendo que a sabedoria prática versa principalmente sobre o particular imediato, que é objeto de percepção (Aristóteles, EN, 1142a 26). Seguindo na análise proposta por Gottlieb, se creio que roubar é o melhor caminho para ajudar os pobres devido a uma avaliação deliberativa, e escolho, de fato, praticar o roubo, então parece haver aqui um erro de razão, de desejo (querer) e de percepção. Isso certamente não poderia ser um caso de boa deliberação. E mais, o querer (que provém de um mesmo caráter, quer vicioso ou não) é responsável pelo fim e pelos meios, de modo que teríamos o desejo moralmente bom do fim conexo à escolha (que implica desejo) má dos meios (o agente teria que ser bom e não ser bom ao mesmo tempo, sob o mesmo aspecto, a saber, o aspecto do querer, dependente direto do caráter e das virtudes morais [ou dos vícios]).

Para Tricot, em nota à tradução do Livro VI, "a realização de uma boa ação é algo indivisível em que a adoção dos meios se confunde com a realização do fim. Se o fim deve ser correto, os meios para atingi-lo devem ser corretos também" (2012, p. 322). Mas, nesse caso, como ficam as ações mistas exemplificadas no Livro III? Aqueles casos em que o agente deve cometer uma ação ignóbil para salvar sua família?

S. Brodie afirma unicamente que "não é claro se o que é falso é um julgamento sobre a efetividade dos meios, quando se alcança um fim por acidente, ou se o que é falso é um julgamento sobre a adequação ética dos meios" (2011, p. 376).

Reeve (2009, p. 194), investigando a deliberação no Livro III, argumenta que Aristóteles "parece reconhecer apenas dois tipos de erro [na deliberação]: primeiro, podemos deliberar bem sobre como alcançar um fim incorreto [...]; 
segundo, podemos encontrar o fim correto 'através de uma falsa dedução [...] sendo falso o termo médio"'. Concordo com Reeve e não parece haver evidência textual para afirmar que no Livro VI o tratamento dado à deliberação seria diferente do Livro III, afirmando apenas agora que o tipo de erro apontado faria referência à imoralidade dos meios.

Penso que (1) exemplifica um caso de habilidade deliberativa em vista de um fim mau, o que indiscutivelmente não é o caso da boa deliberação, por isso é necessário que o fim seja bom. Assim, pode-se pensar que tal habilidade deliberativa (e não a boa deliberação) é uma capacidade de calcular racionalmente o melhor meio para se atingir um fim, seja ele bom ou mau, louvável ou desprezível, como bem aponta Bodéüs (2004, p. 88):

a raiz do vício se encontra não na incapacidade de raciocinar, de deliberar e de encontrar os meios para atingir um objetivo (o ardiloso, se disse, é hábil nisso como o sagaz), mas na incapacidade da inteligência de apreender com verdade o bem que se deve perseguir como um objetivo.

O caso (2) é o que gera discussão e divergências interpretativas sérias com consequências aparentemente importantes à ética aristotélica. Tal caso apresenta um exemplo de erro na deliberação (uso de meio incorreto) e fim bom, o que obviamente não caracteriza a boa deliberação. Entretanto, o que significa "erro na deliberação" ou "meio incorreto" nada tem de óbvio.

O caso (3) insere o critério temporal, no sentido de que toda deliberação tem um tempo oportuno para ser realizada: se rápida demais, pode resultar em decisão errônea, por ser apressada; se lenta demais, pode-se perder o tempo oportuno da ação.

\section{A boa deliberação: discussão e possível resposta}

O caso (2) é citado por intérpretes para justificar a inserção da moralidade dos meios como requisito necessário à boa deliberação. Segue-se, novamente, o trecho:

é possível alcançá-lo [o bem] por um silogismo falso, isto é, alcançar aquilo que se deve fazer, mas não alcançar aquilo através de que se deve fazê-lo - é possível ser falso o termo mediador. Por conseguinte, ainda não é boa deliberação aquela em que se alcança o que se deve alcançar, mas não do modo pelo qual se deveria alcançar.

A interpretação que enfatiza a moralidade dos meios atém-se especialmente à expressão "não do modo pelo qual se deveria alcançar". Contudo, parece simplesmente que a boa deliberação deve consistir em uma habilidade exitosa 
na obtenção do fim, o qual deve ser bom. A deliberação é a capacidade de, dado um fim, investigar o melhor meio para alcançar tal fim. "Melhor meio" toma em conta o que é mais fácil, mais eficaz, no tempo certo. Evidentemente que a boa deliberação, diferentemente da deliberação, deve necessariamente levar em conta um fim bom. No entanto, se se pretende que moralidade seja um requisito dos meios, há que se trazer base textual para tanto dado que não há necessariamente um sentido moral em "modo pelo qual se deveria alcançar".

A sequência do texto sugere simplesmente um erro na premissa menor, ou seja, na apreensão experiencial do particular (caso geralmente citado para ilustrar o incontinente) (cf: Aristóteles, $E N, 1147 \mathrm{a}-1147 \mathrm{~b}$ ), que se assemelha aos loucos, bêbados ou pessoas que dormem. Ora, a phronesis requer experiência e tempo, pois necessita não apenas do conhecimento sobre universais, e.g., "Toda carne leve é saudável", mas especialmente sobre os particulares, que estão presentes em cada circunstância específica de ação, e.g., "A carne de peixe é leve", "Isto é um peixe" etc. Assim, pode-se desconhecer tanto o particular quanto o universal, mas quem tem phronesis acerta sobre ambos, especialmente sobre o particular (Aristóteles, EN, 1142a26). O erro na premissa menor aludido é o caso em que se conhece o universal, a premissa maior (e.g., "todas as carnes leves são saudáveis", ou "todo triângulo têm a soma dos internos iguais a $2 r$ ", ou "toda água pesada é má" etc.), mas se desconhece - ou não se usa (Aristóteles, EN, 1146b 33 - 1147a) - a particular, premissa menor, geralmente devido a fortes apetites ou falta de experiência, que leva ao erro de percepção sobre "esta carne é leve", ou "esta água aqui é pesada", ou "isto que tenho diante dos olhos é um triângulo".

A análise dessa situação em que "atingimos o que devemos [um fim bom], se bem que não pelo meio correto", pode sugerir, ainda, alusão aos seguintes casos: a) alguém alcança um bem por acaso e não como fruto de sua deliberação; b) alguém escolhe o meio mais difícil, menos eficaz e/ou mais longo para se atingir um fim bom sendo que havia uma forma mais rápida e/ou fácil e/ou eficaz; ou ainda, c) alguém delibera tão rapidamente que elementos relevantes passam despercebidos, ou tão demoradamente que se perde o tempo oportuno da ação. O caso "c)" é destacado por Aristóteles como outro exemplo em que o agente não possui boa deliberação, o caso em que se delibera por tempo inadequado: "é possível alcançá-lo [um fim bom] por uma longa deliberação enquanto um outro homem chega a ele rapidamente" (Aristóteles, $E N, 1142$ b24). A correção na deliberação refere-se, portanto, ao fim bom, ao meio eficaz e ao tempo oportuno. O que interessa aqui, portanto, são os casos “a)" e "b)". Ora, em ambos não se trata de alguém que possui a capacidade de boa deliberação: é o caso (a) em que não há deliberação ou o caso (b) em que 
há erro no cálculo mas, a despeito de uma deliberação inábil, atinge-se um bem. Tais são os exemplos que (2) parece ter em vista.

Uma análise das ações mistas, apresentada por Aristóteles no Livro III, pode aclarar a questão, pois parece ser o caso mais marcante da $E N$ no que diz respeito a praticar algo ruim para evitar algo muito pior. Ações mistas são ações passíveis de louvor ou censura, e são, de fato, ações voluntárias, se o que se analisa é o momento da ação, mas que ninguém por "vontade própria" agiria desse modo, como quando se pratica algo ignóbil para se evitar uma tragédia. Um dos exemplos citados em EN 1110a 4-6 é aquele em que se está sujeito à coerção de um tirano:

Há discussão para saber se são voluntárias ou involuntárias as ações praticadas por medo de males maiores antes que com vistas a algo belo; por exemplo, se um tirano ordenasse a alguém fazer algo ignóbil retendo em seu poder pais e filhos que seriam salvos se o fizesse, mas morreriam se não o fizesse. ${ }^{11}$

Neste exemplo, a ação-meio é fazer algo ignóbil; o desejo-fim é salvar seus pais e seus filhos. Ora, a discussão sobre em que medida a boa deliberação é uma correção da deliberação e, especialmente, em que sentido podemos compreender o caso (2), apresentado em EN, 1142b20-24, em que se atinge um fim bom, contudo não pelo meio correto, é enriquecida com a investigação sobre as ações mistas, pois se se quer atribuir um sentido moral à escolha dos meios, então como justificar esse exemplo em que é possível que se delibere bem, pesando razões, escolhendo o melhor meio de agir (com eficiência e a rapidez necessárias) e se atinja um fim bom, a saber, salvar a família ainda que, para isso, deva prestar algum favor ignóbil ao tirano? Se a escolha é salvar a família, não parece razoável afirmar que não há, aqui, boa deliberação. Ou um agente dotado de boa deliberação deixaria sua família morrer, recusando-se a praticar uma ação ignóbil? Assim também é o caso de atirar carga valiosa ao mar durante uma tempestade com o objetivo de salvar a tripulação. Nestes casos, teremos a escolha de meios que, se destacados das circunstâncias, seriam censuráveis, mas que, quando analisadas as circunstâncias e principalmente tendo em vista o fim, que em ambos os casos é bom (salvar a família e salvar a tripulação), tornam-se até louváveis, dado que qualquer homem sensato, segundo Aristóteles, agiria desse modo (EN, 1110a 5-13). No mesmo sentido, diz Pakaluk (2008, p. 126) que um agente virtuoso, em determinadas situações, 
pode cometer atos que, se analisados isoladamente de seu contexto, parecem não ser virtuosos.

O problema de erro na deliberação sobre os meios, se minha leitura estiver correta, é um problema de inabilidade e não de imoralidade. Não há uma cisão entre meios e fins como, posteriormente, propuseram as teorias éticas modernas. Concordo nesse ponto com a interpretação não só de Reeve (2009), mas também de Aubenque (2008, p. 219): “[Aristóteles] pensa no valor moral do fim, mas não [...] no valor moral dos meios. [...] Aristóteles apenas observa que o meio pode ser bem ou mal adaptado ao fim".

Todavia, disso não se segue a desqualificação moral da escolha dos meios, se se entende por "desqualificação moral" a irresponsabilidade moral do agente diante das escolhas que faz, como propõe Aubenque. Discordo fundamentalmente de Aubenque (2008) sobre a razão pela qual a moralidade dos meios não é descartada. Para ele, seria uma falta moral do agente ser inábil para atingir um fim bom:

No entanto, encontramos a dimensão moral por outro viés: se a ação é técnica antes de ser ação moral, ela deve ser tecnicamente bem-sucedida, se se quer que seja moralmente boa. Ignorar as condições técnicas da ação moral, ou seja, se desinteressar pela realização do fim é, no limite, cometer uma falta moral. Não é permitido ser inábil, quando o fim é bom. Se a habilidade não é por si mesma uma virtude, ela é, por certo, uma condição para a virtude, e a excessiva ingenuidade não está longe de ser um vício. (Aubenque, 2008, pp. 219, 220)

A confusão parece estar na diferença entre deliberação, boa deliberação, escolha e ação. A deliberação não implica moralidade, mas sim habilidade. E é apenas aqui que concordo com Aubenque. A boa deliberação, contudo, implica a moralidade do fim. A escolha, por seu turno, deve querer/aceitar/ concordar com o resultado deliberativo para que se siga a ação. E é aqui que se pode atribuir moralidade aos meios, no sentido em que escolha supõe não só razão mas o querer, querer que também é responsável pela bondade ou não dos fins, acarretando a responsabilidade moral do agente sobre suas ações e sobre a formação de seu próprio caráter. O caráter será virtuoso se o agente for prudente, não só porque a prudência supõe boa deliberação, mas também porque supõe as virtudes do caráter. Assim, para que a ação seja moralmente boa, deve haver habilidade na escolha dos meios adequados para se atingir um fim bom:

Em EN VI 13, Aristóteles mostra como a sabedoria prática (phronêsis) e a virtude moral (areté) devem necessariamente colaborar para realizar a ação virtuosa: a primeira calcula os meios e a segunda dá o fim. Aristóteles distingue a sabedoria prática da 
habilidade (deinotês), que também é uma potência capaz de realizar um fim proposto, com a diferença que este fim pode ser tanto nobre quanto perverso (Viano, 2004, p. 115).

Contudo, diferentemente do que propõe Aubenque, a ignorância ou inabilidade na escolha dos meios para atingir um fim bom não implica uma "falta moral", assim como não implica um vício. Pode ser o caso em que não se descubra o melhor meio de se alcançar um bem, ou em que há um engano sobre o melhor modo de alcançá-lo, seja no que diz respeito à eficácia, seja no que diz respeito ao tempo, seja simplesmente no caso em que se desconhece alguma circunstância específica da ação. Nesses casos, o agente não possui habilidade de deliberar. Contudo, o vício é uma disposição de escolha deliberada, o que significa que sua capacidade deliberativa opera perfeitamente bem. Assim, a inabilidade deliberativa não supõe "falta moral". O vício é voluntário, assim como a virtude, e no caso de ignorância ou ingenuidade fala-se de uma ação não voluntária. É possível errar na deliberação simplesmente porque se desconhece alguma das circunstâncias particulares nas quais a ação ocorre. Além disso, no caso analisado, as virtudes morais estão presentes, pois o fim é um bem e é desejado pelo agente.Todos buscam aquilo que lhes aparece como um bem. É da responsabilidade de cada um se aquilo que é tido como um bem é, de fato, um bem real. O modo como o bem aparece para cada um depende da presença ou ausência de virtudes morais, depende, em última instância, do caráter do agente.

Determinada ação poderia, ainda, ser correta (não censurável) apenas acidentalmente, caso em que a ação é realizada involuntariamente e é correta não por decorrer de uma disposição deliberada de escolher os melhores meios para atingir um fim moralmente bom, mas por mero acaso. A deliberação supõe ciência dos elementos circunstanciais e análise do poder de intervenção do agente em tais circunstâncias. Se há poder de intervenção então, voluntariamente, a deliberação exercerá seu papel calculativo e o agente poderá escolher agir segundo a conclusão da deliberação ou não agir.

A escolha deliberada, então, é um processo de decisão sobre os melhores meios para obter um fim. Tal processo é executado tanto pela razão quanto pelos desejos, tendo em vista seu âmbito calculativo e desiderativo. O fim, por seu turno, é posto pelo querer, um fim que impulsiona o agir e que deve ser bom de fato e não apenas parecer bom ao agente (Aristóteles, EN, 1111b 26, 1112b 12-13 e 1112b 34-35). O caráter de alguém pode ser visto tanto nos desejos responsáveis pelos fins quanto na escolha deliberada dos meios.

Imagine-se o caso em que um prudente quer cuidar do bem público (fim). A deliberação do prudente recai sobre como ser eleito para um cargo público (meio), a fim de cuidar do bem público (fim). A deliberação é sobre 
os meios. Será boa deliberação se eficaz/eficiente, feita no tempo oportuno e se for em vistas de um fim bom. No caso, como se trata do prudente, o fim será necessariamente bom: cuidar do bem público. E ele quer isso como um fim em si mesmo. $\mathrm{O}$ fato de a deliberação ter esse fim bom em vista implica a desconsideração de qualquer meio ilícito para obtenção desse fim. E isso porque, se procurar um meio ilícito, não obterá o fim que se propôs desde o início: cuidar do bem público como um fim em si mesmo. A "bondade" do fim e a eficiência/eficácia da deliberação garantem de certa forma a moralidade dos meios, sem que seja necessário exigir da boa deliberação a correção moral dos meios que supõe a cisão entre meios e fins de um modo que Aristóteles não parece ter vislumbrado.

\section{Conclusão}

As noções de moralidade, de dever, e da relação meios/fins, só para citar alguns conceitos caros às éticas moderna e contemporânea, parecem diferir substancialmente das noções éticas aristotélicas. A EN trata da busca pela excelência do indivíduo e apenas uma pequena parcela é dedicada à relação com a alteridade (amizade e justiça). $\mathrm{O}$ estilo investigativo da obra assemelhase a qualquer outro texto aristotélico, da Física à Metafísica. A análise é pautada por categorias, como a de função própria, excesso/falta, do que está ou não está ao nosso alcance, por exemplo, e não de dever/não dever, permitir/proibir. A eudaimonia recebe uma determinação objetiva (Cf. Brüllmann, 2013, p. 133) com a inserção do argumento da função própria, sendo o bem a realização dessa função que, no humano, corresponde à atividade racional da alma desempenhada de modo excelente (Aristóteles, EN, 1097b 25-1098a 20). As noções éticas da ação humana são geralmente exemplificadas com produções no campo das artes ou com a demonstração matemática. Assim, quando Aristóteles afirma que não se delibera sobre o fim, o exemplo é o médico e o orador que não deliberam, respectivamente, sobre se vão querer curar ou persuadir. Quando fala de justiça, define-a como geométrica e aritmética.

Não é diferente a questão da euboulía que trata de encontrar os melhores meios para atingir o fim. A cisão entre meio e fim como elementos independentes na ação não é um problema aristotélico. O "meio" é sempre "meio-para-um-fim", em Aristóteles; estão, portanto, ligados de modo indelével. Consequentemente, é descabido perguntar, à maneira dos modernos, se os fins justificam ou não os meios, dado que a análise moral é da ação decorrente de escolha deliberada efetuada para atingir o fim. $\mathrm{O}$ que pode ser avaliado de modo independente, contudo, não são meios e fins, mas deliberação, boa deliberação e escolha. Não 
há evidência textual acerca da preocupação entre o uso de meios ignóbeis para atingir um fim bom, não que isso fosse moralmente louvável para o pensamento aristotélico, mas porque, se a deliberação é uma boa deliberação, então há não só a necessidade da eficiência dos meios mas também da bondade do fim. A boa deliberação é a característica mais marcante do prudente, referindo-se à correção dos meios. Contudo, a qualidade do fim é, igualmente, critério definicional da boa deliberação dado que a euboulía jamais ocorre para um fim mau. A moralidade dos meios não é mencionada, pois é dependente da moralidade do fim.

Se minha interpretação estiver correta, uma avaliação que se restringe à deliberação não comporta a questão acerca da moralidade, mas tão somente a questão de habilidade no alcance dos fins, interpretação já apontada por Aubenque. Contudo, para Aubenque (2008, pp. 219, 220), a eficácia da deliberação no alcance de um fim bom é condição para a virtude porque "ignorar as condições técnicas da ação moral [...] é, no limite, cometer uma falta moral. Não é permitido ser inábil, quando o fim é bom. Se a habilidade não é por si mesma uma virtude, ela é, por certo, uma condição para a virtude, e a excessiva ingenuidade não está longe de ser um vício" [grifos meus]. Ora, como a ignorância de uma condição técnica, que poderia acarretar erro na deliberação, seria uma falta moral? E como a ingenuidade aproximase do vício? O que parece é que Aubenque faz uma passagem claramente indevida: da inabilidade deliberativa, processo puramente racional que, no caso de inabilidade aqui apontado, refere-se à ignorância ou ingenuidade, Aubenque infere que há um erro moral, aproximando-se do vício. Todavia, não há como justificar tal inferência e parece, em minha leitura, inaceitável a aproximação entre ingenuidade ou ignorância e vício. A deliberação, no caso de um intemperante, por exemplo, pode ser (e geralmente é) extremamente eficaz na obtenção do fim, caso em que o agente é ardiloso (panourgía), não havendo ignorância sobre as circunstâncias particulares da ação e muito menos ingenuidade do agente. Sendo o vício voluntário, o agente deve ser o motor da ação e deve conhecer as circunstâncias particulares nas quais a ação ocorre, donde decorre que ele não pode ser ingênuo ou ignorante sobre as circunstâncias particulares da ação.

Parece equivocada a interpretação de Aubenque (2008), portanto, de que, se o fim é bom, o agente é hábil (no sentido de deliberar com eficácia). Ela, inclusive, contradiz Aristóteles no próprio exemplo analisado (que foi o centro de investigação deste artigo):

é possível alcançá-lo [o bem] por um silogismo falso, isto é, alcançar aquilo que se deve fazer, mas não alcançar aquilo através de que se deve fazê-lo - é possível ser 
falso o termo mediador. Por conseguinte, ainda não é boa deliberação aquela em que se alcança o que se deve alcançar, mas não do modo pelo qual se deveria alcançar.

É o caso, exatamente, em que o fim é bom, mas a deliberação falha no sentido de ignorância de alguma circunstância particular, como o não reconhecimento do termo médio ou da premissa menor. O caso sequer seria possível se, como diz Aubenque (2008, pp. 219, 220), "não é permitido ser inábil, quando o fim é bom". A moralidade pode ser atributo: i) da escolha, em sua parte desiderativa, em agir ou não agir, em seguir ou não a conclusão da deliberação e, portanto, do efetivo poder de intervenção do agente nas circunstâncias em que a ação se realizaria; ii) da boa deliberação (euboulía), dado que implica a bondade do fim; iii) do caráter do agente, se é virtuoso ou não; iv) do fim que se almeja, que é posto pelo querer. A moralidade, portanto, encontrar-se-ia no desejo do que é racionalmente julgado como útil para a obtenção de um fim bom e nunca nos meios nem na pura deliberação.

\section{Referências}

ANGIONI, L. “Aristóteles: Ética a Nicômaco, Livro VI”. Dissertatio, [34], pp. 285300 , verão de 2011.

ARISTÓTELES. "Nicomachean Ethics". Translation and commentary by T. Irwin. Second Edition. Indianápolis: Hackett Publishing Company, 1999.

. "Éthique à Nicomaque". Nouvelle Traduction avec introduction, notes et index par J. Tricot. Paris: Librairie Philosophique J. Vrin 6, Place de La Sorbonne,2012. . "Métaphysique". Présentation et traduction par Marie-Paule Duminil et Annick Jaulin. Paris: Flammarion, 2008.

"Topiques". Organon V. Traduction et notes par J. Tricot. Paris: Vrin, 2012. AUBENQUE, P. “A prudência em Aristóteles". Tradução de M. Lopes. São Paulo: Paulus, 2008.

BODÉÜS, R. "Virtude acabada e vício acabado". Analytica, Vol. 8, Nr. 2, 2004. BRÜLLMANN, P. “A teoria do bem na Ética a Nicômaco de Aristóteles”. São Paulo: Edições Loyola, 2013.

CARVALHO, W., STEFANI, J. "Uma investigação sobre o caráter (éthos) e as virtudes morais na Ética Nicomaqueia”. HYPNOS, Vol. 36, $1^{\circ}$ sem., pp. 93-110, 2016.

GAUTHIER, R. A.; JOLIF, J. Y. "L'Éthique à Nicomaque: Introduction, Traduction et Commentaire", Tome II, Commentaire, Deuxième Partie, Livres V-X. Louvain: Publications Universitaires de Louvain, Éditions Béatrice-Nauwelaerts, 2002.

GOTTLIEB, P. “O silogismo prático”. In: KRAUT, R. et al. (orgs.) Aristóteles: a Ética a Nicômaco. Porto Alegre: Artmed, 2009.

IRWIN, T. "Notes". In: ARISTOTLE. Nicomachean Ethics. Translated, with introduction, notes, and glossary by T. Irwn. 2nd. Ed. Cambridge: Hackett Publishing Co., 1999. 
KENNY, A. “Aristotle's Theory of Will”. London: Duckworth, 1979.

PAKALUK, M. “Aristotle's: Nicomachean Ethics”. New York Cambridge University Press, 2008.

REEVE, C. D. C. “Aristóteles e as virtudes do intelecto". In: KRAUT, R. et al. (orgs.). Aristóteles: a Ética a Nicômaco. Porto Alegre: Artmed, 2009.

TRICOT, J. "Notes". In: ARISTOTLE. Éthique à Nicomaque. Nouvelle Traduction avec introduction, notes et index par J. Tricot. Paris: Librairie Philosophique J. Vrin 6, Place de La Sorbonne, 2012.

VIANO, C. "O que é a virtude natural? (Eth. Nic. VI, 13)". Analytica, Vol. 8, Nr. 2, 2004. ZINGANO, M. "Aristóteles: tratado da virtude moral; Ethica Nicomachea I 13 - III 8”. São Paulo: Odysseus, 2008. 